\title{
Sex Dimorphism of Birth Weight and Length: Evidence Based on Disorders of Sex Development
}

\section{Debora Stabile Romero Amais}

State University of Campinas: Universidade Estadual de Campinas

Tainara Emilia Rodrigues da Silva

State University of Campinas: Universidade Estadual de Campinas

\section{Beatriz Amstalden Barros}

State University of Campinas: Universidade Estadual de Campinas

Juliana Gabriel Ribeiro de Andrade

State University of Campinas: Universidade Estadual de Campinas

Sofia Helena Valente de Lemos-Marini

State University of Campinas: Universidade Estadual de Campinas

Maricilda Palandi de Mello

State University of Campinas: Universidade Estadual de Campinas

Antonia Paula Marques-de-Faria

State University of Campinas: Universidade Estadual de Campinas

Tais Nitsch Mazzola

State University of Campinas: Universidade Estadual de Campinas

\section{Mara Sanches Guaragna}

State University of Campinas: Universidade Estadual de Campinas

\section{Helena Fabbri-Scallet}

State University of Campinas: Universidade Estadual de Campinas

\section{Tarsis Antonio Paiva Vieira}

State University of Campinas: Universidade Estadual de Campinas

\section{Nilma Lucia Viguetti-Campos}

State University of Campinas: Universidade Estadual de Campinas

Andre Moreno Morcillo

State University of Campinas: Universidade Estadual de Campinas

\section{Olaf Hiort}

University of Lubeck: Universitat zu Lubeck

\section{Andrea Trevas Maciel-Guerra}

State University of Campinas: Universidade Estadual de Campinas Gil Guerra-Junior ( $\boldsymbol{\nabla}$ gilguer@unicamp.br)

State University of Campinas: Universidade Estadual de Campinas https://orcid.org/0000-0002-29917678 


\section{Research Article}

Keywords: karyotype, androgens, birth weight, height, gestational age

Posted Date: May 17th, 2021

DOI: https://doi.org/10.21203/rs.3.rs-508679/v1

License: (c) (i) This work is licensed under a Creative Commons Attribution 4.0 International License. Read Full License 


\section{Abstract}

The aim of this study was to verify the influence of $Y$ chromosome and intrauterine androgens production/action on birth weight and length of children with Disorders/Differences of Sex Development (DSD). This was a cross-sectional and retrospective study. Cases of Turner syndrome (TS), complete (XX and $X Y)$, mixed $(45, X / 46, X Y)$ and partial $(X Y)$ gonadal dysgenesis (GD), complete (CAIS) and partial (PAIS) androgen insensitivity syndromes and $X X$ and $X Y$ congenital adrenal hyperplasia (CAH) were included. Such conditions were grouped according to karyotype and to intrauterine production/action of androgens. The sample consisted of 293 cases, 50 with TS, 28 mixed GD, 117 CAH (49 XY and 68 XX), 18 CAIS, 10 PAIS, 30 partial GD, $10 X Y$ and $30 \mathrm{XX}$ complete GD. Birth weight and length were lower in TS and mixed GD when compared to $X Y$ and $X X$. In turn, patients with increased androgen production/action (117 cases) had higher birth weight and length when compared to those with absent (108 cases) and decreased (68 cases) production/action. It was observed a negative influence of the $45, X / 46, X Y$ karyotype in birth weight and a positive influence of increased androgen production/action. Regarding birth length, there was a negative influence of the TS karyotype and of decreased androgen production/action. In conclusion, in DSD, both karyotype, especially with a $45, X$ cell line, and intrauterine androgenic production/action influence sex dimorphism of birth weight and length. It can be inferred that in children with normal karyotype and without a DSD, this dimorphism is mainly due to intrauterine androgenic production or action.

\section{Introduction}

Fetal growth and development are determined by several conditions, including maternal and placental factors and those that are inherent to the fetus, such as its genome. The latter appears as the main determinant of growth at the beginning of fetal life, while in the final stage of pregnancy the intrauterine environment, nutrition and hormonal influence assume a fundamental role [1]. It is known that birth weight in boys is higher than in girls in the general population. Differences in birth weight between the sexes have been reported in humans and in non-human primate species [2]. A population-based retrospective study of 574,358 individuals from southern Australia showed that male fetuses had a lower average gestational age at birth and a higher average birth weight [3]. Moreover, it has been shown that girls are slightly smaller between 8 and 12 weeks and remain smaller throughout pregnancy $[4,5]$.

A large multicenter cross-sectional study evaluated 8,070 low-risk single pregnancies between 16 and 40 weeks of gestation with measurements of biparietal diameter, head and abdomen circumferences and femur length. It was observed that fetal sex was a significant covariate for biparietal diameter and for head and abdomen circumferences, with higher values in male fetuses [6].

Although the cause of the difference in fetal weight and length is not yet fully understood, studies suggest that the presence of the $\mathrm{Y}$ chromosome and androgenic action in the prenatal period may play this role [7]. The interference of the $Y$ chromosome on birth weight was already suggested in the past. Chen et al. [8] evaluated the effects of chromosome abnormalities on birth weight. They concluded that in 
men with sex chromosome abnormalities birth weight tends to decrease when there is an increase in the number of $\mathrm{X}$ chromosomes, while the addition of a $\mathrm{Y}$ chromosome does not correlate with low birth weight [8]. In turn, Turner Syndrome (TS) patients are a good example of how this genotype-phenotype relationship can be inferred from anthropometric data. Although most have normal birth parameters, the frequency of TS in newborns with low birth weight and length is higher than expected $[9,10]$. This is partly explained by the loss or altered expression of genes on the $\mathrm{X}$ chromosome involved with fetal growth [11].

Regarding androgenic action, De Zegher et al. [12] demonstrated that the degree of androgenization is directly related to birth weight, and this factor proved to be superior even to chromosomal sex. In their study, they demonstrated that children with androgen insensitivity syndrome (AIS) with a known mutation in the androgen receptor $(A R)$ gene had a mean birth weight comparable to that of girls and significantly lower of that of unaffected boys and concluded that the difference in birth weight between boys and girls is generated by androgen action.

Boys have greater weight and length at birth compared to girls. Starting from the premise that this result may be due to either the chromosomal constitution or the intrauterine androgenic action, Disorders/Differences of Sex Development (DSD) could be an ideal model for assessing the influence of the karyotype and the intrauterine production and action of androgens in the weight and length at birth. In $46, X Y$ DSD there are cases without androgen production [complete gonadal dysgenesis (GD)] and without androgenic action [complete androgen insensitivity syndrome (CAIS) and in 46,XX DSD there are cases with androgenic overproduction and action [congenital adrenal hyperplasia (CAH) due to 21-hydroxylase deficiency] [13, 14].

Children with $\mathrm{CAH}$ due to 21-hydroxylase deficiency have an increased secretion of adrenal androgens, which in the prenatal period causes virilization of the female external genitalia. Data in the literature demonstrate that prenatal hyperandrogenism also affects the size at birth in newborns with CAH [15]. This analysis started in 1971, in a Canadian study that compared the birth weight of newborns with CAH with their unaffected siblings and normal newborns and found that only girls with $\mathrm{CAH}$ had higher weight than their sisters and female controls [16].

Over the years, several studies have been published comparing anthropometric data of newborns with $\mathrm{CAH}$ and healthy ones. A study in Finland reported that boys and girls with $\mathrm{CAH}$ were longer at birth than healthy children of the same ethnicity [17]. This fact was also confirmed in the study by Balsamo et al., in Italy [18]. In contrast, data from the United Kingdom and Sweden did not show differences between the standard deviation of birth weight in girls and boys with $\mathrm{CAH}$ in relation to national references, and the same occurred in the study by Chalmers et al. $[19,20]$. Thus, it is clear that data published so far in literature are scarce and conflicting.

Therefore, the present study aimed to evaluate the influence of $Y$ chromosome and intrauterine androgens secretion and action on birth weight and length of children with DSD. 


\section{Casuistic And Methods}

The sample consisted of patients diagnosed with DSD evaluated at the Pediatric Endocrinology Outpatient Clinic and the Interdisciplinary Group for the Study of Sex Determination and Differentiation (GIEDDS) at Clinical Hospital of State University of Campinas (UNICAMP), Campinas (Brazil) from June 1988 to December 2017.

Data extracted from the medical files were: gestational age in weeks assessed by Capurro, birth weight and length, presence of genital ambiguity, karyotype and diagnosis of DSD.

In all cases the karyotype was analyzed at the Cytogenetics Laboratory of the School of Medicine of UNICAMP with a count of at least 16 metaphases for homogeneous karyotypes $46, X X$ and $46, X Y$ and 50 metaphases in cases of mosaicism or a 45,X constitution. All cases with a 45,X karyotype were evaluated for SRY, DYZ3 and TSPY genes by polymerase chain reaction at the Human Molecular Genetics Laboratory of the Center for Molecular Biology and Genetic Engineering of UNICAMP. Another inclusion criterion was to have the etiologic diagnosis of DSD confirmed. The non-inclusion criterion was the absence of at least one of the data not available in the medical record.

From the data collected, the variables were classified into:

- Gestational age: in weeks by Capurro [21]

- Gestational age: preterm (<37 weeks), term (between 37 weeks and 41 weeks and 6 days, and postterm if $>42$ weeks) [22]

- Weight $(\mathrm{g})$ and length $(\mathrm{cm})$ at birth: they were transformed into a $\mathrm{z}$ score using the Intergrowth $21 \mathrm{st}$ [23] for gestational age and male or female sex according to the presence or absence of $Y$ chromosome in the karyotype, respectively.

- Intrauterine production or action of androgens: assessed according to the presence of genital ambiguity: female genitalia independent of the karyotype $=$ absence of androgens secretion and(or) action; ambiguous genitalia in any karyotype except $46, X X=$ decreased androgens; male genitalia with karyotype $46, X Y$ or ambiguous with karyotype $46, X X=$ increased androgens

- Karyotype: $45, X$ or other karyotypes of TS without a $Y$ chromosome; $45, X$ and other cell line(s) with a $Y$ chromosome; 46,XY; 46,XX

- Diagnosis: TS (if female genitalia and 45,X karyotype or mosaicism with a 46,XX cell line or with structural $X$ aberration - cases with $Y$ chromosome were excluded), mixed GD (mosaicism $45, X / 46, X Y$ with genital ambiguity and absence of ovarian tissue in gonadal histological evaluation), complete GD (46,XX or 46, XY karyotype, typical female genitalia, with uterus and hypergonadotrophic hypogonadism), XY partial GD (46,XY karyotype, ambiguous genitalia and gonadal histological evaluation showing structural alteration), CAIS (46,XY karyotype, female genitalia, two testicles, mutation in the $A R$ gene), PAIS (partial AIS $=46, X Y$ karyotype, ambiguous genitalia, two testicles, mutation in the $A R$ gene), $\mathrm{CAH}$ (46,XX karyotype with genital ambiguity or inferred 46,XY karyotype with male genitalia with biallelic mutations in the CYP21A2 gene) $[13,14]$. 
The diagnostic groups were divided according to karyotype into: 45, $X$ without $Y$ (TS), 45, X with $Y$ (mixed GD), 46,XY (complete and partial GD, CAIS, PAIS and CAH) and 46,XX (complete GD and $\mathrm{CAH}$ ). The diagnostic groups were also divided according to intrauterine production and(or) action of androgens in absent (TS, XX and XY complete GD and CAIS), decreased (mixed GD, XY partial GD and PAIS) and increased (XX and $X Y C A H)$.

Statistical analysis was performed using SPSS version 21.0 and STATA version 12.0. Quantitative variables were analyzed in median, minimum and maximum and qualitative variables in absolute and relative frequency. Chi-square and Kruskal-Wallis tests and Spearman's correlation coefficient were used. In the multivariate analysis, Quantil Regression was used to model the median. The significance level of $5 \%$ was used in the interpretation of the results.

\section{Results}

The sample consisted of 293 cases, with 50 cases of TS without a Y chromosome, 28 cases of mixed GD, 117 cases with a 46,XY karyotype (49 cases of CAH, 18 of CAIS, 10 of PAIS, 30 of partial GD and 10 of complete GD) and 98 with a 46,XX karyotype (68 of CAH and 30 of complete GD) (Table 1).

Table 1

Data ( $\mathrm{n}$ and \%) of type of karyotype and intrauterine production and action of androgens in 293 cases of DSD.

\begin{tabular}{|lllll|}
\hline Karyotype & \multicolumn{2}{l}{ Androgens } & Total \\
\cline { 2 - 4 } & Absent & Decreased & Increased & \\
\hline $46, X Y$ & $28(23,9)$ & $40(34,2)$ & $49(41,9)$ & 117 \\
\hline $46, X X$ & $30(30,6)$ & $0(0)$ & $68(69,4)$ & 98 \\
\hline $45, X$ without $Y$ & $50(100,0)$ & $0(0)$ & $0(0)$ & 50 \\
\hline $45, X$ with $Y$ & $0(0)$ & $28(100,0)$ & $0(0)$ & 28 \\
\hline Total & 108 & 68 & 117 & 293 \\
\hline
\end{tabular}

Regarding karyotype, the $z$ score of birth weight was significantly lower in the TS group without $Y$ compared to the $46, X Y$ karyotype $(p=0.008)$ and $46, X X$ karyotype $(p=0.003)$, and the same occurred when birth length was compared ( $p<0.0001$ in both). Birth weight and length $z$ score was also significantly lower in $45, X / 46, X Y$ cases (mixed GD) when compared to $46, X Y$ and $46, X X$ karyotypes ( $p<$ 0.0001 in all analyzes). There was no significant differences between TS without $Y$ and mixed GD in relation to birth weight $(p=0.06)$ and length $(p=0.186)$, the same occurring between $X Y$ and $X X$ karyotypes for birth weight $(p=0.07)$ and length $(p=0.374)($ Table 2$)$. 
Table 2

Weight and length z score at birth of 293 cases of DSD according to the karyotype.

\begin{tabular}{|llll|}
\hline Karyotype & & z Birth Weight & z Birth Length \\
\hline TS without $Y$ & $\mathrm{n}$ & 50 & 50 \\
\cline { 2 - 4 } & Median & $-0,20$ & $-1,02$ \\
\cline { 2 - 4 } Mixed GD & Minimum - Maximum & $-3,47-1,68$ & $-4,58-1,63$ \\
& $\mathrm{n}$ & 28 & 28 \\
\cline { 2 - 4 } & Median & $-0,66$ & $-1,48$ \\
\hline XY & Minimum - Maximum & $-2,98-1,49$ & $-4,90-0,67$ \\
& $\mathrm{n}$ & 117 & 117 \\
\cline { 2 - 4 } & Median & 0,03 & $-0,35$ \\
\cline { 2 - 4 } & Minimum - Maximum & $-1,78-2,51$ & $-3,25-2,57$ \\
\hline & $\mathrm{n}$ & 98 & 98 \\
\cline { 2 - 4 } & Median & 0,20 & $-0,28$ \\
\cline { 2 - 4 } & Minimum - Maximum & $-2,21-2,90$ & $-3,57-5,94$ \\
\hline Mixed GD: Mixed Gonadal Dysgenesis; TS: & Turner syndrome; Kruskall-Wallis test \\
\hline
\end{tabular}

According to intrauterine androgens production and(or) action, the groups were divided into absent (108 cases), decreased (68 cases) and increased (117 cases). The group with increased androgens had birth weight $(p<0.0001)$ and length $(p<0.0001)$ significantly higher than the group of absent and decreased androgens. There was no significant difference between the group with absent androgens and decreased androgens in relation to birth weight $(p=0.064)$ and length $(p=0.071)$ (Table 3$)$. 
Table 3

Weight and length $z$ score at birth of 293 cases of DSD according to the intrauterine production or action of androgens.

\begin{tabular}{|llll|}
\hline Androgens & & z Birth Weight & z Birth Length \\
\hline Absent & $\mathrm{n}$ & 108 & 108 \\
\cline { 2 - 4 } & Median & $-0,02$ & $-0,53$ \\
\cline { 2 - 4 } & Minimum - Maximum & $-3,47-1,68$ & $-4,58-1,63$ \\
\hline \multirow{2}{*}{ Decreased } & $\mathrm{n}$ & 68 & 68 \\
\cline { 2 - 4 } & Median & $-0,31$ & $-0,92$ \\
\cline { 2 - 4 } & Minimum - Maximum & $-2,98-1,47$ & $-4,90-2,12$ \\
& $\mathrm{n}$ & 117 & 117 \\
\cline { 2 - 4 } & Median & 0,47 & 0,01 \\
\cline { 2 - 4 } & Minimum - Maximum & $-2,21-2,90$ & $-3,57-2,57$ \\
\hline Kruskall-Wallis test & & \\
\hline
\end{tabular}

An association was observed between the intrauterine androgens production and(or) action and gestational age (premature or term) $(\chi 2=39.511 ; D F=2 ; p<0.0001)$, with more term cases with increased androgens and more premature cases with absent androgens (Table 4).

Table 4

Association data between gestational age and intrauterine production or action of androgens in 293 cases of DSD.

\begin{tabular}{|lllll|}
\hline Gestational Age & \multicolumn{2}{l}{ Androgens } & \multirow{2}{*}{ Total } \\
\cline { 2 - 4 } & Absent & Decreased & Increased & \\
\hline Premature & $49(66,2) *$ & $14(18,9)$ & $11(14,9)$ & 74 \\
\hline Term & $59(26,9)$ & $54(24,7)$ & $106(48,4) *$ & 219 \\
\hline Total & 108 & 68 & 117 & 293 \\
\hline Chi-square test; ${ }^{*} \mathrm{p}<0.0001$ & & & \\
\hline
\end{tabular}

There was no association between the karyotype and gestational age (premature or term) $(\chi 2=6.328$; DF $=3 ; p=0.097)$. There was also no correlation between gestational age (in weeks) with birth weight $(r=$ $-0.14 ; p=0.811)$ or length $(r=0.17 ; p=0.767)$.

The multivariate analysis with Quantile regression for the median presented the following models (Table 5): 
Qualitative variables assume the value 1 for yes and 0 for no; and gestational age in weeks.

Qualitative variables assume the value 1 for yes and 0 for no; and gestational age in weeks.

Table 5

Data of Quantile regression for the median z score of weight and length at birth in 293 cases of DSD.

\begin{tabular}{|llllll|}
\hline z Birth Weight & Coefficient & SD & t & p & CI 95\% \\
\hline 45,X with Y & $-0,702$ & 0,18 & $-3,95$ & 0,0001 & $-1,057$ a $-3,455$ \\
\hline Increased androgen & 0,559 & 0,11 & 5,00 & 0,0001 & 0,338 a 0,778 \\
\hline Gestational age & $-0,665$ & 0,03 & $-2,27$ & 0,024 & $-0,127$ a $-0,009$ \\
\hline Constant & 2,517 & 1,14 & 2,21 & 0,028 & 0,276 a 4,758 \\
\hline z Birth Length & & & & & \\
\hline 45,X with Y & $-0,964$ & 0,402 & $-23,59$ & 0,0001 & $-1,044$ a $-0,883$ \\
\hline 45,X without Y & $-0,638$ & 0,322 & $-19,77$ & 0,0001 & $-0,701$ a $-0,574$ \\
\hline Increased androgen & 0,35 & 0,026 & 13,18 & 0,0001 & 0,297 a 0,402 \\
\hline Decreased androgen & $-0,166$ & 0,034 & $-4,63$ & 0,0001 & $-0,233$ a $-0,098$ \\
\hline Gestational age & $-0,032$ & 0,005 & $-5,39$ & 0,0001 & $-0,043$ a $-0,020$ \\
\hline Constant & 0,866 & 0,225 & 3,84 & 0,0001 & 0,422 a 1,309 \\
\hline
\end{tabular}

\section{Discussion}

In the present study, the use of DSD cases allowed to verify the influence of the $Y$ chromosome and the intrauterine androgens production and(or) action on birth weight and length.

Regarding karyotype, it was demonstrated that TS patients without a $Y$ chromosome had significantly lower birth weight and length compared to the $46, X Y$ and $46, X X$ karyotypes. Similar findings in the literature show that girls with TS are 3.1 to 8.8 times more likely to be born with lower weight than in the general population, in addition to being shorter at birth, with growth deficit due to haploinsufficiency of the SHOX gene (Short Stature Homeobox, OMIM *312865) located on the short arm of the X chromosome (Xp22.33) [24-26].

There was no significant difference between TS without $Y$ and mixed GD in relation to birth weight and length, due to the fact that patients with $45, \mathrm{X} / 46, \mathrm{XY}$ karyotype share the $45, \mathrm{X}$ cell line with TS and can also share some or all of its comorbidities, such as prenatal growth deficit $[27,28]$. Analyzing these two groups, TS and mixed GD, an important influence of the chromosomal constitution is evidenced when compared to the hormonal synthesis, since in mixed GD there is some androgenic secretion (decreased androgens), while in TS there is no androgen synthesis (absent androgens). 
There were no significant differences between the $X Y$ and $X X$ karyotypes for birth weight and length. It must be considered that in groups $X X$ and $X Y$ there were different types of DSD with increased, decreased or absent androgenic production or action, therefore the difference described in the literature, that boys $(46, \mathrm{XY})$ have higher birth weight and length compared to girls $(46, \mathrm{XX})$, is not applicable. Thus, it can be inferred that the androgenic effect may play an important role in birth weight and length and may even be more important factor than chromosomal sex [12].

Regarding the androgenic influence on birth weight and length, data in the literature are conflicting. In the present study, in relation to groups classified according to the intrauterine androgens production and(or) action, patients with increased androgens had significantly higher birth weight and length in relation to those in which androgens are absent or decreased.

Hughes et al. showed a significantly higher proportion of boys with hypospadias with birth weight less than $2,500 \mathrm{~g}(19.6 \%)$ compared to the other boys (5.5\%) and girls (6\%) [29], reflecting the influence of decreased androgen level (presence of hypospadias). Twin pregnancies are another possible model to assess the androgenic effect, revealing that the weight of the female twin is higher when her partner is male, possibly due to the androgenic effect [30].

On the other hand, Miles et al. showed that the anthropometric difference between the sexes at birth is not due to prenatal exposure to androgens, but due to the presence of the $Y$ chromosome. Their results showed that newborns with CAIS had weight at birth similar to normal male babies and the birth weight in babies with CAH was not higher when compared to healthy ones [19]. Dorr et al. found similar results when comparing data on babies with $\mathrm{CAH}$ and the population reference group [15].

The association observed between the karyotype and the intrauterine production or action of androgens, with more cases of increased androgens in 46,XY (CAH in males) and 46,XX karyotypes and more cases of absent androgens in cases $45, X$ without $Y$ and decreased androgens in cases $45, X$ with $Y$, is probably due to the types of DSD selected for this study.

There were no androgens in TS (cases $45, X$ without $Y$ ) due to the gonadal abnormality of these patients, even leading to estrogen deficit $[26,31]$. A similar situation occurs in mixed GD $(45, X$ with $Y)$, characterized by a hormonal profile with increased gonadotropins due to GD and decreased androgen production, regardless of the degree of genital ambiguity [32].

Regarding the association between the intrauterine androgens production and(or) action and gestational age, there were more patients born at term with increased androgens and more premature patients with absent androgens. Studies have shown the influence of androgen on birth weight and length, but not an influence on prematurity. The etiology of premature birth is not completely understood due to the complex interaction between genetic, environmental and host factors [33]. However, advances are being achieved in this elucidation. Studies also report that there are more premature births among boys than girls between 24 and 37 weeks of gestational age [34]. 
In animal models, it was identified the IGF1R gene (Insulin-like Growth Factor receptor 1, OMIM * 147370) related to the predisposition to premature birth and two other genes linked to $\mathrm{X}$ chromosome $-A R$ (Androgen Receptor, OMIM *313700) and IL2RG gene ( $\gamma$ subunit of the receptor of IL-2, OMIM *308380) (35). CAG repeats of $A R$ exon-1 have been associated with premature delivery, with more CAG repeats in premature birth when compared to term birth. CAG repetition encodes a polyglutamine present in the $A R$ transactivation domain and longer chains stop $A R$ transactivation activity in vitro, while short chains lead to increased $A R$ activation, resulting in hyperandrogenism [36]. Thus, hypoandrogenism may be associated with prematurity as demonstrated in this sample.

As a synthesis of the results of the present study, quantile regressions were created for the median birth weight and length. In relation to the median birth weight, there was a negative influence of the karyotype $45, X / 46, X Y$ and gestational age and a positive influence of androgen. In relation to the median birth length, there was a negative influence of the karyotype $45, X / 46, X Y$, gestational age, TS karyotype without $Y$ and decreased androgen and positive influence of increased androgen.

\section{Conclusion}

In children with DSD, birth weight and length were associated with the karyotype and the etiology of DSD evidenced by the intrauterine production or action of androgens. It can be inferred that in children without DSD and with a normal karyotype, the sex dimorphism of weight and length at birth is related to the production or action of androgens in intrauterine life.

\section{Abbreviations}

AIS: androgen insensitivity syndrome

$\mathrm{CAH}$ : congenital adrenal hyperplasia

CAIS: complete androgen insensitivity syndrome

DSD: disorders/differences of sex development

GD: gonadal dysgenesis

PAIS: partial androgen insensitivity syndrome

TS: turner syndrome

\section{Declarations}

Funding Sources: none

Conflict of Interest Statement: the authors declare no conflict of interest. 
Availability of data material: https://doi.org/102524/redu/URVCSI

Author Contributions: DSTA, TER, ATM-G and GG-J: review the literature; DSTA, TER, BAB, JGRA, APM-F, AMM, OH, ATM-G and GG-J: designed the study; MPM, TNM, MSG, HF-S, TAPV, NLV: performed experiments for the diseases diagnosis (karyotype, FISH and molecular studies). All authors co-wrote and revised the paper.

\section{Ethics Declarations:}

\section{Ethics Approval:}

All procedures performed in studies involving human participants were in accordance with the ethical standards of the institutional or national research committee and with the 1964 Helsinki Declaration and its later amendments or comparable ethical standards. Approval of this study was obtained from the institutional review board of State University of Campinas (UNICAMP) (CAAE: 0340.0.146.000-06).

Consent to participate: N/A - retrospective study

Consent for publication: N/A - retrospective study

\section{References}

(1) Cunningham FG, Gant NF, Leveno KJ (2001) Williams Obstetrics. 21st ed. New York: McGraw-Hill, 2001.

(2) Smith RJ, Leigh SR (1998) Sexual dimorphism in primate neonatal body mass. J Hum Evol 34(2):173201. doi: $10.1006 /$ jhev.1997.0190.

(3) Verburg PE, Tucker G, Scheil W, Erwich JJHM, Dekker GA, Roberts CT (2016) Sexual dimorphism in adverse pregnancy outcomes - a Retrospective Australian population study 1981- 2011. PLoS One 11(7): e0158807. doi: 10.1371/journal.pone.0158807

(4) Bukowski R, Smith GCS, Malone FD, Ball RH, Nyberg DA, Comstock CH, Hankins GD, Berkowitz RL, Gross SJ, Dugoff L, Craigo SD, Timor-Tritsch IE, Carr SR, Wolfe HM, D'Alton ME; FASTER Research Consortium (2007). Human sexual size dimorphism in early pregnancy. Am J Epidemiol 165(10):12161218. doi: $10.1093 /$ aje/kwm024

(5) Peacock JL, Marston L, Marlow N, Calvert SA, Greenough A (2012) Neonatal and infant outcome in boys and girls born very prematurely. Pediatr Res 71(3):305-310. doi: 10.1038/pr.2011.50

(6) Rizzo G, Prefumo F, Ferrazzi E, Zanardini C, Di Martino D, Boito S, , Aiello E, Ghi T; SIEOG Working Group on Fetal Biometric Charts (2016) The effect of fetal sex on customized fetal growth charts. J Matern Fetal Neonatal Med 29(23):3768-3775. doi: 10.3109/14767058.2016.1149565 
(7) Poyrazoglu S, Darendeliler F, Ahmed SF, Hughes I, Bryce J, Jiang J, Rodie M, Hiort O, Hannema SE, Bertelloni S, Lisa L, Guran T, Cools M, Desloovere A, Claahsen-van der Grinten HL, Nordenstrom A, Holterhus PM, Kohler B, Niedziela M, Krone N (2017) Birth weight in different etiologies of disorders of sex development. J Clin Endocrinol Metab 102(3):1044-1050. doi: 10.1210/jc.2016-3460

(8) Chen AT, Chan LY, Falek A (1971) The effects of chromosome abnormalities on birth weight in man. Hum Hered 21(6):543-556. doi: 10.1159/000152490

(9) Hagman A, Wennerholm U-B, Källén K, Barrenäs M-L, Landin-Wilhelmsen K, Hanson C, Bryman I (2010) Women who gave birth to girls with Turner syndrome: maternal and neonatal characteristics. Hum Reprod 25(6):1553-1560. doi: 10.193/hmrep/deq060

(10) Even L, Cohen A, Marbach N, Brand M, Kauli R, Sippell W, Hochberget Z (2000) Longitudinal analysis of growth over the first 3 years of life in Turner's syndrome. J Pediatr 137(4):460-464. doi:

$10.1067 / \mathrm{mpd} .2000 .109110$

(11) Wisniewski A, Milde K, Stupnicki R, Szufladowicz-Wozniak J (2007) Weight deficit at birth and Turner's syndrome. J Pediatr Endocrinol Metab 20(5):607-613. doi: 10.1515/jpem.2007.20.5.607

(12) De Zegher F, Francois I, Boehmer AL, Saggese G, Müller J, Hiort O, Sultan C, Clayton P, Brauner R, Cacciari E, Ibáñez L, Van Vliet G, Tiulpakov A, Saka N, Ritzén M, Sippell WG (1998) Androgens and fetal growth. Hormone Res Paediatr 50(4):243-244. doi: 10.1159/000023284.

(13) Lee PA, Houk CP, Ahmed SF, Hughes IA; International Consensus Conference on Intersex organized by the Lawson Wilkins Pediatric Endocrine Society and the European Society for Paediatric Endocrinology (2006) Consensus statement on management of intersex disorders. International Consensus Conference on Intersex. Pediatrics 118(2): e488-500. doi: 10.1542/peds.2006-0738

(14) Lee PA, Nordenström A, Houk CP, Ahmed SF, Auchus R, Baratz A, Baratz Dalke K, Liao LM, Lin-Su K, Looijenga LH 3rd, Mazur T, Meyer-Bahlburg HF, Mouriquand P, Quigley CA, Sandberg DE, Vilain E, Witchel S; Global DSD Update Consortium (2016) Global Disorders of Sex Development update since 2006: perceptions, approach and care. Horm Res Paediatr 85(3):158-180. doi: 10.1159/000442975

(15) Dörr HG, Penger T, Albrecht A, Marx M, Völkl TMK (2019) Birth size in neonates with Congenital Adrenal Hyperplasia due to 21-hydroxylase deficiency. J Clin Res Pediatr Endocrinol 11(1):41-45. doi: 10.4274/jcrpe.galenos.2018.2018.0149

(16) Qazi QH, Thompson MW (1971). Birthweight in congenital virilizing adrenal hyperplasia. Arch Dis Child. 46(247):350-352, 1971. doi: 10.1136/adc.46.247.350

(17) Jaaskelainen J, Voutilainen R (1997) Growth of patients with 21-hydroxylase deficiency: an analysis of the factors influencing adult height. Pediatr Res 41(1):30-33. doi: 10.1203/00006450-19970100000005 
(18) Balsamo AM, Di Pasquale G, Salzano G, Baronio F, Bombaci S, De Luca F (2006) Birth length and weight in congenital adrenal hyperplasia according to the different phenotypes. Eur J Pediatr 165(6):380383. doi: 10.1007/s00431-005-0075-y

(19) Miles HL, Gidlöf S, Nordenström A, Ong KK, Hughes IA (2010) The role of androgens in fetal growth: observational study in two genetic models of disordered androgen signalling. Arch Dis Child Fetal Neonatal Ed 95(6):F435-438. doi: 10.1136/adc.2009.173575

(20) Chalmers LJ, Doherty P, Migeon JC, Copeland KC, Bright BC, Wisniewski AB (2011) Normal sex differences in prenatal growth and abnormal prenatal growth retardation associated with 46,XY disorders of sex development are absent in newborns with congenital adrenal hyperplasia due to 21-hydroxylase deficiency. Biol Sex Differ 2:5. doi: 10.1186/2042-6410-2-5

(21) Capurro H, Konichezky S, Fonseca D, Caldeyro-Barcia R (1978) A simplified method for diagnosis of gestational age in the newborn infant. J Pediatr 93(1):120-122. doi: 10.1016/s0022-3476(78)80621-0

(22) (2013) ACOG Committee Opinion No 579: Definition of term pregnancy. Obstet Gynecol 122(5):11391140. doi: 10.1097/01.AOG.0000437385.88715.4a

(23) Villar J, Ismail LC, Victora CG, Ohuma EO, Bertino E, Altman DG, Lambert A, Papageorghiou AT, Carvalho M, Jaffer YA, Gravett MG, Purwar M, Frederick IO, Noble AJ, Pang R, Barros FC, Chumlea C, Bhutta ZA, Kennedy SH; International Fetal and Newborn Growth Consortium for the 21 st Century (INTERGROWTH-21st) (2014) International standards for newborn weight, length, and head circumference by gestational age and sex: the Newborn Cross-Sectional Study of the INTERGROWTH21st Project. Lancet. 38(9946):857-868. doi: 10.1016/S0140-6736(14)60932-6

(24) Bernasconi S, Larizza D, Benso L, Volta C, Vannelli S, Milani S, Aicardi G, Berardi R, Borrelli P, Boscherini B, et al (1994) Turner's syndrome in Italy: familial characteristics, neonatal data, standards for birth weight and for height and weight from infancy to adulthood. Acta Paediatr 83(3):292-298. doi: 10.1111/j.1651-2227.1994.tb18097.x

(25) Rongen-Westerlaken C, Corel L, van den Broeck J, Massa G, Karlberg J, Albertsson-Wikland K, Naeraa RW, Wit JM (1997) Reference values for height, height velocity and weight in Turner's syndrome. Swedish Study Group for GH treatment. Acta Paediatr 86(9): 937-942. doi: 10.1111/j.1651-2227.1997.tb15174.x

(26) Gravholt CH, Andersen NH, Conway GS, Dekkers OM, Geffner ME, Klein KO, Lin AE, Mauras N, Quigley CA, Rubin K, Sandberg DE, Sas TCJ, Silberbach M, Söderström-Anttila V, Stochholm K, van Alfen-van derVelden JA, Woelfle J, Backeljauw PF; International Turner Syndrome Consensus Group (2017) Clinical practice guidelines for the care of girls and women with Turner syndrome: proceedings from the 2016 Cincinnati International Turner Syndrome Meeting. Eur J Endocrinol 177(3):G1-G70. doi: 10.1530/EJE-170430 
(27) Tosson H, Rose SR, Gartner LA (2010) Children with 45,X/46, XY karyotype from birth to adult height. Horm Res Paediatr 74(3):190-200. doi: 10.1159/000281468

(28) Ounsted C, Ounsted M (1970) Effect of Y chromosome on fetal growth-rate. Lancet 2(7678):857-858. doi: 10.1016/s0140-6736(70)92021-0

(29) Hughes I.A, Northstone K, Golding J, ALSPAC Study Team (2002) Reduced birth weight in boys with hypospadias: an index of androgen dysfunction? Arch Dis Child Fetal Neonatal. 87(2):150-151. doi: 10.1136/fn.87.2.f150

(30) Jahanfar S, Lim K (2016) The impact of gender on anthropometric measures of twins. Twin Res Hum Genet 19(6):652-658. doi: 10.1017/thg.2016.57

(31) Gravholt C.H, Viuff M.H, Brun S, Stochholm K, Andersen NH (2019) Turner syndrome: mechanisms and management. Nat Rev Endocrinol 15(10):601-614. doi: 10.1038/s41574-019-0224-4

(32) Johansen ML, Hagen CP, Rajpert-De Meyts E, Kjærgaard S, Petersen BL, Skakkebæk NE, Main KM, Juul A (2012) 45,X/46,XY mosaicism: phenotypic characteristics, growth, and reproductive function - a retrospective longitudinal study. J Clin Endocrinol Metab 97(8):E1540-E1549. doi: 10.1210/jc.2012-1388

(33) Park B, Khanam R, Vinayachandran V, Baqui AH, London SJ, Biswal S (2020) Epigenetic biomarkers and preterm birth. Environ Epigenet 6(1):1-12. doi: 10.1093/eep/dvaa005

(34) Ingemarsson I (2003) Gender aspects of preterm birth. BJOG 110(Suppl 20):34-348. doi: $10.1016 / \mathrm{s} 1470-0328(03) 00022-3$

(35) Karjalainen MK, Huusko JM, Ulvila J, Sotkasiira J, Luukkonen A, Teramo K, Plunkett J, Anttila V, Palotie A, Haataja R, Muglia LJ, Hallman M (2012) A potential novel spontaneous preterm birth gene, AR, identified by linkage and association analysis of X chromosomal markers. PLoS One 7(12):e51378. doi: 10.1371/journal.pone.0051378

(36) Bezold KY, Karjalainen MK, Hallman M, Teramo K, Muglia LJ (2013) The genomics of preterm birth: from animal models to human studies. Genome Med 5(4): 34 . doi: 10.1186/gm438 